\title{
Research Summary on the Investment Loan Linkage Business Model of Commercial Bank
}

\author{
Qian Chen ${ }^{1, a}$, Mu Zhang 2,b,* \\ ${ }^{1}$ Guizhou Institute For Urban Economics and Development, Guizhou University of Finance and \\ Economics, Guiyang Guizhou 550025, China \\ ${ }^{2}$ Guizhou Institution for Technology Innovation\& Entrepreneurship Investment, Guizhou University \\ of Finance and Economics, Guiyang Guizhou 550025, China \\ ${ }^{3}$ School of Finance, Guizhou University of Finance and Economics, Guiyang Guizhou 550025, \\ China \\ a249086572@qq.com, brim_007@163.com
}

Keywords: Investment loan linkage, Venture capital, Lowercase letters, Commercial bank loan, Venture capital organization, Commercial bank, Venture enterprise.

\begin{abstract}
In order to further study the investment loan linkage business of commercial banks, this paper reviews the theories and empirical literatures of commercial banks carry out the investment loan linkage business in the field of venture capital in recent years. Summarized the main motivations and advantages of commercial banks to carry out investment loan linkage business; channels and models of commercial banks to carry out investment loan linkage business, the mechanism of the commercial banks to carry out investment loan linkage business; practice and risk control and other aspects of the research results of commercial banks to carry out investment loan linkage business. The above contents are briefly reviewed, and hope to be able to promote the development of commercial bank investment business linkage.
\end{abstract}

\section{商业银行投贷联动业务模式研究综述}

\author{
陈倩 $1, \mathrm{a}$, 张目 $2, \mathrm{~b},{ }^{*}$ \\ 1贵州财经大学贵州城镇经济与发展研究院, 花溪, 贵阳, 贵州, 中国 \\ 2贵州财经大学贵州科技创新创业投资研究院, 花溪, 贵阳, 贵州, 中国 \\ 3 贵州财经大学金融学院, 花溪, 贵阳, 贵州, 中国 \\ a249086572@qq.com, brim_007@163.com
}

关键词：投贷联动；风险投资；商业银行贷款；风险投资机构；商业银行；创业企业

中文摘要. 为进一步深入的开展对商业银行投贷联动业务的研究, 本文梳理了近年来关于商 业银行介入风险投资领域, 开展投贷联动业务的主要理论和实证文献。主要概述了商业银行 开展投贷联动业务的动因与优势; 商业银行开展投贷联动业务的渠道和模式、商业银行开展 投贷联动业务的机制; 商业银行开展投贷联动业务的实践及风险防控等方面的研究成果, 并 进行了简要评述。以期推动商业银行投贷联动业务的发展。 


\section{1. 引言}

我国金融体系以间接融资为主，商业银行擅长为传统重资产行业提供金融服务，而科技 型中小企业轻资产的特点导致了商业银行在对科技型中小企业提供信贷支持时面临着风险与 收益极度不匹配的困境。因此投贷联动业务是商业银行为解决科技型中小企业融资难问题, 通过一定渠道介入风险投资领域的一种创新融资模式。2015年3月，国务院发布《关于深化体 制机制改革加快实施创新驱动发展战略的若干意见》，提出要选择符合条件的银行业金融机 构，探索试点投贷联动。2016年3月，“投贷联动” 作为助推创新创业的金融动力，被首次写 入《2016年政府工作报告》。2016年4月20日，银监会、科技部、人民银行联合印发了《关于 支持银行业金融机构加大创新力度开展科创企业投贷联动试点的指导意见》，标志着投贷联 动试点工作正式启动，也标志着商业银行进行股权投资的综合化经营正式起步。本文通过对 近年来国内外关于商业银行介入投资领域开展投贷联动业务的相关文献进行分析与总结, 以 期推动商业银行投贷联动业务的发展。

\section{2. 商业银行开展投贷联动业务的动因与优势}

国外大多数的商业银行是混业经营, 商业银行介入 $\mathrm{VC} / \mathrm{PE}$ 作为商业银行开展投资银行业 务的一种实践较多，在商业银行进入投资领域的动因与优势方面，Fiet和Fraser (1994） ${ }^{[1]}$ 通 过调研获得银行机构对于介入风险投资看法，使用股票价格指数分析介入风险投资实现组合 多样化带来的影响, 对银行进入这个行业的净效益进行研究, 从而得出银行进入风险投资领 域的潜在收益。Mason和Harrison（1996） ${ }^{[2]}$ 提出在非正式的风险资本市场上银行具有优势, 应当积极参与创业投资, 改变由于宏观经济变化以及银行贷款行为变化造成的中小企业面临 着融资更加困难的环境的现状。Jordi Canals（1997） ${ }^{[3]}$ 提出开展私募股权投资等业务不仅可 以改善商业银行当前投资渠道狭窄产品单一的现状，获得更高的投资收益，还可以通过覆盖 企业现在与未来的投资风险从而降低商业银行经营所承担的总体风险。Joseph F Sinkey (2002) ${ }^{[4]}$ 认为商业银行的优势有三点：客户资源众多、信息优势强大、营销网络庞大。因此商业银 行开启投资业务可以很快形成规模效益，提高效率，形成强大的竞争力。

国内研究方面，王中、市英丹（2008） ${ }^{[5]}$ 认为商业银行由于自身特性无论是在资金规模、 客户资源还是交叉销售方面都有着其他金融机构无法比拟的优势，商业银行介入私募股权投 资市场并开展竞争既推动了私募股权融资的发展，也拓展了自身的业务领域，增加了中间业 务收入。鲍丹丹（2008） ${ }^{[6]}$ 认为银行业在我国最具资金实力、有着长期投资的经验，对风险 企业投资虽然有着较高风险，但只要有效控制风险将商业银行部分资金投入风险投资市场， 将对解决风险投资的困境有极大帮助。李卢霞（2010） ${ }^{[7]}$ 认为资金实力最为雄厚的商业银行 参与PE业务有着极大的优势。商业银行拥有的充足的资金储备远远高于其他金融机构，由于 自身业务掌握着大量企业发展信息有着较强的项目选择能力, 同时还拥有着较为完善的专业 技能和人员储备, 是开展PE业务的重要保证。李佳音（2010） ${ }^{[8]}$ 认为从商业银行的角度可以 看出私募股权投资是满足客户多元化需求、提高银行服务水平和盈利能力的重要业务, 商业 银行由于有着优质的客户资源、拥有专业的风险管理团队、雄厚的资金实力, 为商业银行开 展投贷联动创造了有利条件。

\section{3. 商业银行开展投贷联动业务的模式和机制}

鉴于国外投贷联动模式的发展, 我国学者也逐渐将研究视角聚焦在这一创新融资模式上, 一些学者提出我国商业银行也可以在一定的前提条件下进入投资领域。康芸（2007） ${ }^{[9]}$ 指出 风险投资对于知识型产业的中小企业成立与发展起到重要影响，在保证信贷资金安全的前提 下探索商业银行介入风险投资领域的途径、介入创业投资领域对于扩大中小企业的融资渠道 以及提高商业银行资金收益、扭转经营困境有着重要的意义。张陆洋、刘崇兴和范建年 (2007)

${ }^{[10]}$ 提出商业银行雄厚的资金实力是创业投资金融支持体系的重要支撑，并对如何引导商业银 
行将其富余资金投入至风险投资领域进行分析。刘飞宇、蒲勇健（2009） ${ }^{[11]}$ 通过分析我国商 业银行介入风险投资领域的现有模式的特点以及局限性, 提出要从近期与远期两个层次考虑 引入风险投资机制，考虑风险与收益问题，设计出更适合介入风险投资领域的创新模式。一 方面提升商业银行的成长和发展的能力, 另一方面推动我国风险投资领域的快速发展，为商 业银行未来全面进入风险投资领域提供参考。王元龙、田野（2009） ${ }^{[12]}$ 通过分析我国商业银 行参与创业投资的现状以及制约因素，指出我国商业银行可以通过加大贷款力度、深化中介 服务、积极介入创业投资基金设立等形式进一步参与到创业投资中，同时也要注意加强风险 管理和人才积累。

在商业银行进入投资领域后，针对我国商业银行参与风险投资的模式，我国部分学者也 进行了相关研究。李雯友 (2004) ${ }^{[13]}$ 提出, 商业银行在政策允许的条件下可适度参与风险投 资，可以通过特别投资部门自己筹建风险投资公司、入股风险投资基金或者投资二板市场三 种方式参与风险投资。康芸、刘曼红（2010） ${ }^{[14]}$ 提出了我国商业银行参与风险投资的三种形 式：内部组件风险投资公司、入股风险投资基金、购买中小板或创业板股票。目前来看我国 商业银行参与风险投资的应采取前两种形式相结合的模式，即贷款与企业股权、期权挂钩。 何峥（2004） ${ }^{[15]}$ 在对比国内外商业银行参与风险投资的模式的基础上，结合我国发展现状提 出，我国商业银行可以通过参股风险投资公司参与风险投资，与风险投资公司共同出资设立 风险资金，通过分红获得收益。何小锋、胡渊（2008） ${ }^{[16]}$ 通过对国内外金融机构投资FOF案 例的研究，分析了私募股权投资基金领域FOF的运作状况与管理方式，以及FOF出现与发展 的优势所在。选择花旗银行为其中一个案例分析了金融机构构建包含FOF的私募股权投资体 系必要性，并提出政策建议。赵光明（2010） ${ }^{[17]}$ 提出我国商业银行PE业务虽然受到政策性限 制, 但依然采取变通的方法进入了 PE领域, 目前已经形成了特批模式、子公司模式、财务顾 问模式和理财产品模式四种基本的业务模式。

商业银行、企业以及风险投资机构三个主体参与的风险收益分配是投贷联动成立的基础。 林琳（2001） ${ }^{[18]}$ 构建了在多方约束条件下，商业银行、企业和风险投资机构的三方博峦模型, 并通过分析得出三方博奕的最优决策, 从而对不同类型的企业会选择何种融资方式进行考察。 晏文隽（2009） ${ }^{[19]}$ 通过构建银行、风险投资机构、创业企业家三者间的委托代理模型，分析 了我国投贷联盟的风险收益分配问题，研究了在风险投资中三种投资组合的委托代理关系， 从而得出最优权益分配。肇启伟、刘璐和姚露（2012） ${ }^{[20]}$ 对投贷联动成立的基础以及准入条 件进行了研究。在Catherine Casemate（2003） ${ }^{[21]}$ 模型的基础上，利用公司金融理论和委托代 理理论, 分析探讨了投贷联盟的两种模式并构建这两种模式的数理模型。从风险收益角度对 比了在采取不同的投贷联盟模式下对科技型中小企业、风投机构以及商业银行的准入门槛。

\section{4. 商业银行开展投贷联动业务的实践及风险防控}

我国商业银行在开展投贷联动业务的实践中，应当通过借鉴国外的投贷联动模式健全自 身发展模式。王婵、田瑞增（2012） ${ }^{[22]}$ 认为可以通过借鉴美国硅谷银行投资模式，建立健全 商业银行的创业企业信用担保体系、丰富与创业投资公司的合作模式、建立专业行业金融团 队、完善增值服务体系，通过金融创新实现商业银行与创业投资的双赢。中国银行业协会商 业银行投贷联动研究课题组（2015） ${ }^{[23]}$ 提出，我国应借鉴英国中小企业成长基金（Business Growth Fund，BGF）尝试构思打造 “中国版BGF” - “小微企业成长基金”。进一步改善国 内小微企业, 特别是成长型科技企业的融资环境, 对投贷联动模式进行深入探讨, 开拓出一 条多方共赢的新路径。蔡洋萍、肖勇光 (2014) ${ }^{[24]}$ 以国家开发银行为例, 探讨我国商业银行 投贷联动模式选择构想。提出国开行的中小企业信贷业务通过与外部机构进行合作，将机构 所拥有的资源汇聚在平台内, 解决了产业投资项目来源问题。通过产业投资平台与信贷合作 部门相互推选客户，在节省成本同时降低投资与贷款项目风险。

在商业银行投贷联动业务的逐渐展开中，关于风险防控的相应的对策建议则显得尤为重 要。胡志金鍂（2010） ${ }^{[25]}$ 认为商业银行是否可以成功参与风险投资的决定性因素就在于风险控 
制的好坏，所以设计一套完善的，将内部风险控制机制和外部的金融监管体系很好地融合在 一起风险控制机制对于商业银行来讲是至关重要的。胡艳、刘霞（2010） ${ }^{[26]}$ 对商业银行开展 投资银行业务所面临的各种风险进行研究分析, 并针对这些风险提出了防范措施, 包括实行 综合投资分散风险，成立对应的部门对投资业务进行精细管理等。卜祥瑞（2015） ${ }^{[27]}$ 提出投 贷联动模式是一种创新的融资活动, 但是它并没有改变银行在借贷活动中的基础性风险管控 目标, 存在着六大法律风险。商业银行必须对投贷联动的相关法律风险有着非常明确地认识, 加大相关业务流程的整合与培训力度，完善相关多元化纠纷解决机制，加快修订《商业银行 法》等法律规范。

\section{5. 简要评述}

本文主要概述了商业银行开展投贷联动业务的动因与优势；商业银行开展投贷联动业务 的渠道和模式、商业银行投贷联动业务的机制; 商业银行开展投贷联动业务的实践及风险防 控等方面的研究成果。可以看出, 目前国内外学术界和业界针对商业银行投贷联动机制的理 论与实证研究成果相对较少。因此，对投贷联动下风险投资对科技型中小企业信用风险的影 响机理及其实证检验、投贷联动下风险投资对科技型中小企业贷款的增长效应等问题的研究， 才刚刚起步。本项目将探索投贷联动下风险投资对科技型中小企业信用风险的影响机理, 并 在此基础上提出完善商业银行投贷联动机制的政策建议。

\section{致谢}

本文为国家自然科学基金地区项目《贷款风险补偿资金对科技型中小企业信贷配给的影 响机理研究》(71263011)的阶段性成果之一。

\section{References}

[1] R. M. Hill, The single-vendor single-buyer integrated production-inventory model with a generalized policy, European Journal of Operational Research, vol. 97, pp. 493-499, 1997.

[2] Mason C M, Harrison R T, The UK Clearing Banks and the Informal Venture Capital Market, International Journal of Bank Marketing, vol. 14, pp. 5-14, 1996.

[3] Canals J, Universal Banking: International Comparisons and Theoretical Perspectives, Oxford University Press, 1997.

[4] Joseph F Sinkey, Commercial Bank Financial Management, Bei jing: China Financial Publishing House, 2002.

[5] Zhong Wang, Yingdan Bian, The Private Equity Financing from the Perspective of Commercial Bank, Finance Forum, vol. 10, pp. 10-14, 2008.

[6] Dandan Bao, Study On the Model of Commercial Banks' Barticipation in Venture Capital Investment, Fudan University, 2008.

[7] Luxia Li, Qian Wan, Yuan Li. Status, Obstacles and Strategies of Investment of Commercial Banks in Private Equity, Finance Forum, vol. 2, pp. 35-41, 2010.

[8] Jiayin Li, Analysis on the Prospect of China's Commercial Banks to Participate in the PE Fund, China Finance, vol. 17, pp. 51-52, 2010.

[9] Yun Kang, Discussion on the Venture Capital Investment of Commercial Bank Credit Funds, China Venture Capital \& High-Tech, vol. 1, pp. 58-60, 2007.

[10]Luyang Zhang, Chongxin Liu, Jiannian Fan, Venture Capital Market Research, Shanghai: Fudan University Press, 2007. 
[11]Feiyu Liu, Yongjian Pu, Innovation Pattern Design of China's Commercial Banks in the Field of Risk Investment, Statistics \& Decision, vol. 21, pp. 129-131, 2009.

[12] Yuanlong Wang, Ye Tian, Five Magic Weapon for Commercial Banks to Participate in Venture Capital, China Venture Capital, vol. 3, pp. 37-39, 2009.

[13]Jiyou Li, A Study on Appropriate Participation of Commercial Banks in Venture Capital Investment, Modern Economic Research, vol.4, pp. 48-50, 2004.

[14] Yu Kang, Manhong Liu, Thoughts on the Venture Capital Investment of China's Commercial Banks, Science \& Technology Progress and Policy, vol. 27, pp. 9-12, 2010.

[15]Zheng He, Yuehong Zhang, Demian Chen, Study on the Possibility and the Framework for Commercial Bank Going into Venture Capital Field in China, East China Economic Management, vol. 1, pp. 126-130, 2004.

[16]Xiaofeng $\mathrm{He}$, Yuan $\mathrm{Hu}$, Investment of Financial Institutions in Private Equity Funds of Funds-Based on Case Study, Reformation \& Strategy, vol. 12, pp. 61-66, 2008.

[17] Guangming Zhao, Discussion on the PE Business Model of China's Banking Industry and Its Supervision, Commercial Times, vol. 26, pp. 80-81, 2010.

[18]Lin Lin, Comparison between Bank Financing and Venture Capital Financing and the Three Side Game Model under the Condition of Multiple Constraints, Studies of International Finance, vol. 5, pp. 18-23, 2001.

[19] Wenjusn Yan, Ju-e Guo, The Study on Principal Agent Relationship among Venture Capitalist, Bank and Enterpriser, Journal of Management Sciences, vol. 2, pp. 91-98, 2009.

[20]Qiwei Zhao, Lu Liu, Lu Yao, Analysis of Multiple Access Restriction Model of Investment Loan Alliance, Soft Science, vol. 26, pp. 137-140, 2012.

[21]Casamatta C, Financing and Advising: Optimal Financial Contracts with Venture Capitalists, Social Science Electronic Publishing, vol. 58, pp. 2059-2086, 2002.

[22] Chan Wang, Ruizeng Tian, Research on the Investment-Loan Mode between Commercial Bank and Venture Capital, Enterprise Vitality, vol. 6, pp. 5-10, 2012.

[23]China Banking Association Commercial Bank Investment Loan linkage Research Group, With Reference to Explore a New Model of Commercial Bank and British Investment Loan Linkage "SME Growth Fund" Enlightenment, China Banking, vol. 7, pp. 18-33, 2015.

[24] Yangping Cai,Yongguang Xiao, Investment Loan Linkage Model of China's Commercial Banks Choose Concept - to the National Development Bank as an Example, Northern Economy and Trade, vol. 7, pp. 174-175, 2014.

[25]Zhixing Hu. Study on the Mode Sselection and Risk Control of Commercial Banks Participating in Venture Capital Investment, Shanghai: Fudan University, 2010.

[26] Yan Hu, Xia Liu, Analysis on the Risk Management of China's Commercial Banks in Venture Capital Investment, Modern Business Trade Industry, vol. 3, pp. 152-154, 2010.

[27]Xiangrui Bian, Dialysis Investment Loan Linkage Patterns of Six Recessive Legal Risk, China Banking, vol. 7, pp. 78-81, 2015. 